\title{
Práticas de prazer na escrita de autoras brasileiras contemporâneas
}

\author{
Pleasure Practices in the Writing of Contemporary Brazilian Authors
}

Prácticas de placer en la escritura de autoras brasileñas contemporáneas

Sophia Beal ${ }^{*}$

\begin{abstract}
Resumo
Mulheres (tanto cis quanto transgênero) experimentam, muitas vezes, inquietações em torno do prazer corporal devido a repressões e a dinâmicas hegemônicas de poder. As expectativas patriarcais, autoritárias, machistas, coloniais e capitalistas sobre os valores, os papéis e os "lugares" sociais das mulheres contribuem para o estabelecimento desse incômodo. Assim, o conforto de uma mulher com seu próprio corpo e a satisfação de suas necessidades e seus desejos - o que chamo aqui de práticas de prazer - são atos políticos, curativos e libertadores que afrontam normas sociais, particularmente para mulheres com identidades interseccionais e marginalizadas. Baseando-se na teoria do erótico, de Audre Lorde, e no conceito do "direito ao devaneio", de Tatiana Nascimento, defendo que a prosa e a poesia de escritoras brasileiras LGBTQI+ e/ou negras, publicadas nos últimos cinco anos (desde 2016), atentam para a validação de uma ampla gama de práticas de prazer. Entre essas autoras, encontram-se Carol Bensimon, Cristiane Sobral, Katiana Souto, Kika Sena, Nanda Fer Pimenta, Piera Schnaider e Tatiana Nascimento. Embora as mulheres estejam usando a escrita criativa para afirmação de práticas de prazer há muito tempo, cada nova geração contribui de modo mais acentuado para esse esforço, reiterando que ainda há muito trabalho a ser feito e expandindo as concepções de prazer corporal para além de normas hetero, cis, eurocêntricas e monogâmicas.
\end{abstract}

Palavras-chave: Tatiana Nascimento, Cristiane Sobral, Piera Schnaider, Kika Sena.

\section{Abstract}

People who identify as women (both cis- and transgender) often experience unease around bodily pleasure due to hegemonic power dynamics and repressions. Patriarchal, authoritarian, sexist, colonial and capitalist expectations about a woman's worth, societal role and "place" all influence this unease. Therefore, the process of a woman feeling good in her body and attending to its needs and desires - what I refer to as a pleasure practice - is a political, healing and liberating act that involves defiance of social norms, particularly for women with intersectional, marginalized identities. Drawing on Audre Lorde's theory of the erotic and Andrea Saad Hossne Universidade de São Paulo (USP) Tatiana Nascimento's concept of the "direito ao devaneio", I argue that the prose and poetry of Brazilian LGBTQI+ and/or Black women writers, written in the last five years, reveal an increased attention to validating a wide range of pleasure practices. These authors include Carol Bensimon, Cristiane Sobral, Katiana Souto, Kika Sena, Nanda Fer Pimenta, Piera Schnaider and Tatiana Nascimento. Although women have been using creative writing to affirm their pleasure practices for a long time, each new generation adds

\section{Resumen}

Las mujeres (tanto cis como transgénero) a menudo experimentan preocupaciones sobre el placer corporal debido a la represión y la dinámica de poder hegemónicas. Las expectativas patriarcales, autoritarias, sexistas, coloniales y capitalistas sobre los valores, roles y "lugares" sociales de las mujeres contribuyen al establecimiento de dicho malestar. Así pues, la comodidad de una mujer con su propio cuerpo y la satisfacción de sus necesidades y deseos - lo que llamo aquí prácticas de placer - son actos políticos, curativos y liberadores que atentan contra las normas sociales, particularmente para las mujeres con identidades interseccionales y marginadas. Basándome en la teoría de lo erótico, de Audre Lorde, y en el concepto "direito ao devaneio", de Tatiana Nascimento, sostengo que la prosa y la poesía de escritoras LGBTQI+ y/o negras brasileñas publicadas en los últimos cinco años (desde 2016) revelan una creciente atención hacia la validación de una amplia gama de prácticas de placer. Entre las autoras se encuentran Carol Bensimon, Cristiane Sobral, Katiana Souto, Kika Sena, Nanda Fer Pimenta, Piera Schnaider y Tatiana Nascimento. Aunque las mujeres han estado utilizando la escritura creativa para afirmar

\footnotetext{
*University of Minnesota, Minneapolis, Minnesota, Estados Unidos. (Dorcid.org/0000-0003-3023-7466. E-mail: sfbeal@umn.edu
} 
to this effort by asserting that there is still work to be done and by expanding conceptions of bodily pleasure beyond hetero, cis, Eurocentric, monogamous norms.

Keywords: Tatiana Nascimento, Cristiane Sobral, Piera Schnaider, Kika Sena. las prácticas de placer desde hace mucho tiempo, cada nueva generación contribuye con más fuerza a este esfuerzo, por lo que reitera que todavía queda mucho trabajo por hacer y amplía las concepciones del placer corporal más allá de las normas heterosexuales, cis, eurocéntricas y monógamas.

Palabras-clave: Tatiana Nascimento, Cristiane Sobral, Piera Schnaider, Kika Sena.

Mulheres (tanto cis quanto transgênero) experimentam, muitas vezes, inquietações em torno do prazer corporal devido a repressões e a dinâmicas hegemônicas de poder. Esse mal-estar pode estar ligado à objetificação, à exotização, à imposição de padrões de beleza inalcançáveis e/ou à pressão social que as mulheres sofrem para anulação de seus desejos. As expectativas patriarcais, autoritárias, machistas, coloniais e capitalistas sobre os valores, os papéis e os "lugares" sociais das mulheres contribuem para o estabelecimento desse incômodo (Beauvoir, 1949/1973; Butler, 1990; Gonzalez, 1988/2021; Lorde, 1978/2019; McKittrick, 2006; Moraga, 1993; Ribeiro, 2017; São Bernardo, 2020; Valentine, 1996). Assim, o conforto de uma mulher com seu próprio corpo e a satisfação de suas necessidades e seus desejos - o que chamo aqui de práticas de prazer - são atos políticos, curativos e libertadores que afrontam normas sociais, particularmente para mulheres com identidades interseccionais e marginalizadas. Baseando-se na teoria do erótico, de Audre Lorde, e no conceito do "direito ao devaneio", de Tatiana Nascimento, defendo que a prosa e a poesia de escritoras brasileiras LGBTQI+ e/ou negras, publicadas nos últimos cinco anos (desde 2016), atentam para a validação de uma ampla gama de práticas de prazer. Entre essas autoras, encontram-se Carol Bensimon, Cristiane Sobral, Katiana Souto, Kika Sena, Nanda Fer Pimenta, Piera Schnaider e Tatiana Nascimento. ${ }^{1}$ Embora as mulheres estejam usando a escrita criativa para afirmação de práticas de prazer há muito tempo, cada nova geração contribui de modo mais acentuado para esse esforço, reiterando que ainda há muito trabalho a ser feito e expandindo as concepções de prazer corporal para além de normas hetero, cis, eurocêntricas e monogâmicas. ${ }^{2}$

Em 1949, Simone de Beauvoir afirmou que "não se nasce mulher, torna-se mulher", um argumento que abriu caminho para reflexões sobre a performatividade de gênero e a construção social da identidade (1973, p. 330). Concordo com a definição que Regina Dalcastagnè e Virgínia Maria Vasconcelos Leal atribuem às mulheres, "como um grupo heterogêneo e complexo, formado por identidades múltiplas e contraditórias que não se esgotam no sexo biológico ou no gênero, mas que, em grande medida, partilham pressões e expectativas impostas por uma sociedade que continua marcada pela dominação masculina" $(2015$, p. 9). As escritoras analisadas neste ensaio estão comprometidas com o questionamento crítico e a ampliação da definição da categoria mulher em seus próprios termos e a partir de vários lugares de fala (Ribeiro, 2017).

As vivências femininas de sofrimento ou de negação da oportunidade de experimentar prazer não são uniformes e, obviamente, são influenciadas por identidades interseccionais e por fatores

\footnotetext{
${ }^{1}$ Há outras autoras cujos trabalhos eu poderia ter selecionado para explicar este argumento. Escolhi exemplos que considerei particularmente pungentes, e reconheço a subjetividade envolvida na minha seleção. Também sei que minha posicionalidade - sou uma mulher estadunidense branca, cis, hetero, abastada e com grande interesse de pesquisa na escrita contemporânea brasiliense informa minhas perspectivas e meus hábitos de leitura.

${ }^{2}$ Muitos dos mais provocativos, belos e elogiados textos literários escritos por mulheres brasileiras antes da década de 1980 tratam de personagens femininas expressando desejos que não podem concretizar. Textos de Carmen Dolores (pseudônimo de Emília Moncorvo Bandeira de Melo), Rachel de Queiroz, Clarice Lispector, Carolina Maria de Jesus, Edla van Steen e Lygia Fagundes Telles, por exemplo, são corajosos com relação ao desejo de suas protagonistas. A década de 1980 trouxe mais textos preocupados com mulheres realizando seus desejos sexuais, como a peça "Boca molhada de paixão calada" (1980), de Leilah Assunção. Nas décadas seguintes, mais mulheres com identidades marginalizadas interseccionais publicaram prosa e poesia que aclamam suas práticas de prazer de maneiras que desafiam os padrões heteropatriarcais. Para mais informações sobre o tema, ver Dalcastagnè e Leal (2015), FerreiraPinto (2004), Figueiredo (2020) e Melo, Othero e Duarte (2019).
} 
individuais. Lélia Gonzalez (2021), por exemplo, observou que os movimentos feministas na América Latina foram cegos às experiências de mulheres negras latino-americanas, um problema que persiste até hoje. Optei por analisar textos de mulheres que se identificam como LGBTQI+, negras e/ou de baixa renda porque seu prazer corporal tem sido mais policiado e restringido do que o de mulheres brancas, hetero e cisgênero. Além disso, as oportunidades de publicação para autoras LGBTQI+, negras e/ou de baixa renda têm sido historicamente escassas (Dalcastagnè, 2012). Uma das mobilizações mais fortes no setor de publicação brasileiro da última década foi a criação de editoras independentes especializadas em questões identitárias, como Abadia Catadora, Avá, Malê, Maria Cobogó, Louva Deusas, Mjiba e Padê Editorial (Brito, 2019; Tennina, 2017). Cinco das autoras aqui analisadas publicaram pela Padê Editorial, uma editora fundada por Tatiana Nascimento e Bárbara Esmênia e dedicada à divulgação de mais escritoras negras e LGBTQI+. Selecionei uma pluralidade de expressões do prazer corporal das mulheres - sexual; não-sexual; relacionado ao amor-próprio, ao amor monogâmico e ao amor poligâmico; presente em relacionamentos hetero e LGBTQI+ - para valorizar a legitimidade de todas essas práticas de prazer.

As intelectuais negras e LGBTQI+ Audre Lorde, Tatiana Nascimento e Adrienne Maree Brown defendem a criação de espaço (na vida, no ativismo e na escrita) para o prazer em detrimento do sofrimento. Lorde, no seminal ensaio "Usos do erótico", emprega o termo erótico para se referir a um poder das mulheres que está enraizado em sua capacidade de sentir profundamente, um poder que as normas sociais suprimiram. Ela escreve que nós, mulheres:

ao começarmos a reconhecer nossos sentimentos mais profundos, desistimos de nos satisfazer com o sofrimento, a autonegação e com o embotamento que muitas vezes parece ser sua única alternativa a isso em nossa sociedade. Nossos atos contra a opressão se tornam íntegros, motivados e empoderados desde dentro. Em contato com o erótico, fico menos disposta a aceitar a impotência, ou aqueles outros estados de ser que não me são próprios, como a resignação, o desespero, o autoapagamento, a depressão, a autonegação (Lorde, 2019, p. 33).

Em sua antologia O prazer como ativismo: a política do sentir-se bem (2019), que é em grande parte inspirada por e inclui o ensaio de Lorde, Brown também clama por uma maior atenção ao prazer, em oposição ao sofrimento:

O conceito de sofrimento é central para muitas de nós, quer sejamos ativistas, articuladoras políticas, qualquer uma tentando mudar o mundo... muito de como somos atraídas para a comunidade e mantidas na comunidade parte de uma solidariedade construída em torno do nosso sofrimento... o que não é libertador. Simplesmente não é isso. Isso não nos define. O sofrimento não é o que nos motiva. [...] Devemos experimentar prazer e união (Brown, 2019, p. 48).

Para muitas escritoras negras e LGBTQI+, denunciar o preconceito violento e as dores que ele causa é tão urgente que se torna prioridade na escrita. Contestando essa pressão para delação da violência no contexto do trabalho de escritoras queer e negras, Tatiana Nascimento propõe uma "escrita preta lgbt como direito ao devaneio, libertação do dever de denunciar" (2018, p. 15). Recorrendo à poesia de Kika Sena como exemplo, Nascimento afirma que: "assim como temos muito contra o que resistir pra sobreviver a partir da força, temos muito de fartura, abundância, sabedoria, devaneio, conexão ancestral que nos permite (bem) viver a partir da graça" (2018, p. 16). A elaboração criativa de uma prática de prazer não normativa expõe a opressão por meio da celebração. Essa expressão mantém a política da denúncia, mas com o júbilo do devaneio. Djamila Ribeiro, em sua concepção de lugar de fala, ressalta a necessidade de

deslocamento do pensamento hegemônico e a ressignificação das identidades, sejam de raça, gênero, classe para que se pudesse construir novos lugares de fala com o objetivo de possibilitar voz e visibilidade a sujeitos que foram considerados implícitos dentro dessa normatização hegemônica (2017, p. 45).

As autoras aqui analisadas operam esse deslocamento através de expressões de prazer. Seguindo a visão de Dalcastagnè, a literatura brasileira deve representar e ser escrita por uma grande variedade de pessoas porque elas "vão ver e expressar o mundo de maneiras diversas" (Dalcastagnè e Leal, 2015, p. 43) e suas perspectivas podem questionar o status quo. 


\section{Kika Sena}

O poema "ondas", de Sena, compõe seu livro Periférica (2017), publicado pela Padê Editorial. A autora se identifica como "mulher trans y travesti, preta y periférica" (Sena, 2017, p. 5). Desviandose do feminicídio e da violência contra mulheres trans, temas centrais no livro, "ondas" reflete sobre os poderes curativos da natureza, da alimentação e da conexão com a ancestralidade e com as raízes geográficas. O poema foi escrito quando a autora morou em Brasília, e o eu-lírico se imagina sobrevoando a capital e lembrando de Alagoas, seu estado natal. O sujeito poético deleita-se com o prazer (ou a memória do prazer) de nadar na Praia do Francês, de comer manga até seu rosto ficar amarelo e de se sentir abraçada por Iemanjá. O poema inclui os versos:

quase escuto um blues

mas me vem mesmo é um canto pra Iemanjá

que é mais melhor

que abraça a gente.

onde ainda o mar me alcança

plaino azul pelo céu brasiliense

quase me esquecendo de aterrissar

voo leve

lenta

calma

como a calma do mar

quentinho da praia do francês

o mesmo

que me acolhe a alma.

onde ainda o mar me alcança

atiro uma pedra numa mangueira e voo

junto com a pedra

que é pra poder beijar a manga

antes dela cair

e volto

amarela

lembrando da criança barriguda que fui $(2017$, p. 19).

A cor azul no poema conecta passado e presente, alto e baixo, perto e longe. Através do céu azul da capital, Sena acessa a memória das águas azuis de Alagoas. As imagens do mar e de Iemanjá acolhendo a alma sugerem as propriedades curativas do contato com a natureza, do movimento físico e da ligação a uma prática de fé e à ancestralidade negra. Quatro vezes, o poema repete o verso: "onde ainda o mar me alcança". Em um livro de poesia tão focado no trauma dos crimes de ódio, "ondas" apresenta o prazer do autocuidado. Por causa da qualidade onírica de um eu-lírico que sobrevoa Brasília para acessar memórias curativas e o canto de Iemanjá, o poema se revela afrofuturista, pois parte da tradição da diáspora negra para imaginar um futuro livre de violência. ${ }^{3}$ Sena dedica "ondas" à sua mãe, descrita pela autora, no início da coleção, como uma "puta macumbeira e pobre", que foi vítima de abuso físico e verbal $(2017$, p. 10). Essa dedicatória sugere o processo de cura de um trauma multigeracional. A forma com que Sena alterna denúncias e devaneios em seu livro dialoga com as reflexões de Nascimento sobre o trabalho de artistas negras e LGBTQI+: "a gente, como poeta, artista, escritorx, performer, temos nos acostumado com o dever da denúncia e tamos esquecendo do direito ao devaneio" (2018, p. 18). Lucía Tennina articula ideia semelhante, apontando uma tensão entre "[d]e um lado a mulher militante, do outro a mulher que deseja" (2015, p. 79). Sena - voando sobre Brasília com o rosto tingido de manga - atende a esse direito à fantasia e ao desejo. A artista mostra como a poesia pode ser política, divertida e corporal ao mesmo tempo.

\footnotetext{
${ }^{3}$ Referindo-se ao afrofuturismo, Brown afirma que: "A ideia de ver e criar um futuro a partir de uma perspectiva cuja linhagem descende de uma semente africana, de algo mais antigo e diferente do ocidente, se mostra curativa para mim” (2017, p. 98).
} 


\section{Nanda Fer Pimenta}

Pimenta é uma mulher negra, LGBTQI+, de baixa renda e neurodiversa. No poema " 31 ", de seu livro Sangue (2018) - também publicado pela Padê Editorial - a autora escreve sobre como o prazer do amor-próprio contribui para a afirmação de sua dignidade e a valorização de sua subjetividade:

Hoje vou aos poucos tirando minha roupa

Olhando em frente ao espelho meu corpo

Nada diferente, lindo belo meu corpo

Dilato o olhar, vou além vou aos poucos

A minha boca se derrete entre os seios

Meu corpo não é corpo é mundo

Espalhando aos poucos pelo quarto, por inteiro

Beirando ao delírio, eu amo meu corpo mundo

Eu não existo mais

Instantes que se dilatam em verdades

Janelas, sombras que vão e voltam envolvem meu corpo

As palavras em meu corpo mundo, perdem o sentindo (2018, p. 42).

O poema de Pimenta repudia o sofrimento e a autonegação cultivados pelas normas de beleza capitalistas, optando, ao contrário, por afirmar "lindo belo meu corpo". Como elabora Tennina, no contexto da poesia paulistana escrita por mulheres negras e periféricas:

a produção poética das escritoras da periferia não somente questiona o lugar relegado à mulher na periferia e nos espaços hegemônicos, mas também, e ao mesmo tempo, provoca uma tensão em relação ao campo literário brasileiro, enquanto deixa em evidência de forma indireta a não problematização da experiência da mulher negra nas produções assinadas por escritoras de trajetória letrada $(2015$, p. 74$)$.

Dada a objetificação histórica e a exotização de mulheres negras na literatura brasileira e global, a poesia de Pimenta também afirma o direito dessas mulheres à vocalização pública de seu prazer corporal. O poema termina inesperadamente com o gerúndio "sentindo", problematizando os limites da linguagem para a expressão de sentimentos profundos. O leitor fica com a impressão de que o desenvolvimento do amor-próprio não é conclusivo, mas consiste em processo emergente e contínuo. Os exemplos subsequentes envolvem o amor erótico compartilhado entre duas ou mais pessoas.

\section{Piera Schnaider}

Schnaider, uma escritora branca LGBTQI+, publicou sua coleção de poemas Água viva (2018) como parte da série cole-sã escrevivências, da Padê Editorial. Essa série, a mesma da qual participa Katiana Souto, foi dedicada à "autopublicação artesanal de narrativas LBTs". O poema sem título de Schnaider na página 23, que começa com "me toca", brinca com as semelhanças entre como um músico produz música tocando um violão e uma amante produz prazer tocando o eu-lírico. O poema é uma celebração do prazer erótico não normativo que, como a música, possui um poder que desafia a explicação racional:

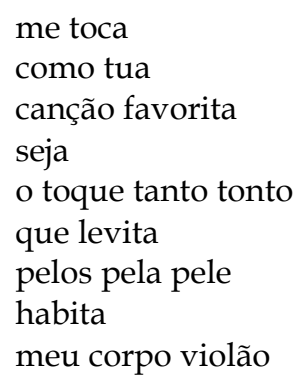




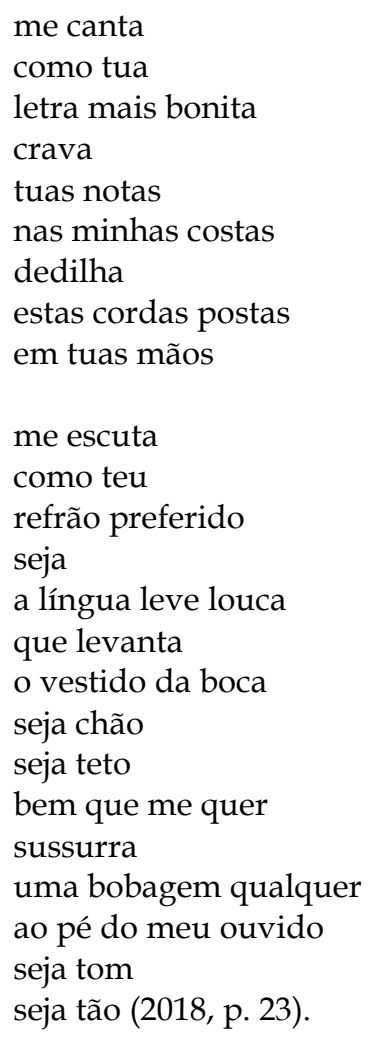

O poema termina com a declaração inacabada "seja tão", um convite aberto à aceitação e ao acolhimento de uma série de possíveis prazeres e realizações. Nesse sentido, o poema pode ser lido como uma afronta à constatação, identificada por Lorde, de que as mulheres "foram criadas para temer o sim dentro de nós mesmas, nossos mais profundos desejos" (Lorde, 2019, p. 32). O verso "seja tão" reconhece essas vontades, deixando seus mistérios e suas particularidades ao preenchimento da imaginação dos leitores.

\section{Carol Bensimon}

O romance de Bensimon O clube dos jardineiros de fumaça (2017), publicado pela Companhia das Letras, é um raro exemplo de texto que trata o desejo poliamoroso de forma não exotizada. A personagem Tamara conta como uma relação romântica com seu marido, Will, e Sarah começou:

Pisco o olho, tô apaixonada por ela. Nunca tinha me acontecido uma coisa dessas, mas eu não fico nervosa nem nada, só deixo ver aonde isso vai me levar. Acontece que Will e Sarah se conhecem uns dias depois e também se apaixonam... Sarah também tá encantada. Encantada pelos dois. Não por um e por outro em separado, eu acho, mas por essa terceira coisa, essa força poderosa, essa única personalidade que a gente era junto, você acha isso possível? [...] Nós vivemos algo incrível por dois anos e meio, eu, Will e Sarah. A gente não chama isso de poliamor. É só amor, certo? (2017, p. 46).

Tamara não se arrepende de suas práticas de prazer. No romance, o poliamor não é apresentado como pior ou melhor do que a monogamia, mas como uma escolha válida e um potencial lugar de prazer. O romance de Bensimon Todos nós adorávamos caubóis (2013) também aborda a bissexualidade dessa mesma forma não exotizada, normalizando assim relacionamentos românticos que têm sido tratados na ficção de forma caricatural. 


\section{Tatiana Nascimento}

Em 2016, a escritora negra e LGBTQI+ Nascimento publicou a coleção de poesia lundu, pela Padê Editorial. O poema "lundu," (uma dança cantada de origem banto) conecta o desejo erótico não normativo a marés oceânicas, tradições africanas ancestrais, natureza, música, dança e diáspora negras. "lundu," ressoa a concepção de Lorde do erótico como uma força poderosa dentro das mulheres, acessada através do que nos faz sentir alegria:

Outra maneira importante de funcionamento do erótico é a ênfase aberta e destemida da minha capacidade de alegria. Assim como meu corpo se expande com a música e se abre em resposta a ela, escutando atentamente aos ritmos mais profundos, então tudo aquilo que eu sinto também se abre para a experiência eroticamente satisfatória, seja dançando, construindo uma estante de livros, escrevendo um poema, examinando uma ideia $(2019$, p. 31).

O poema une elementos sensuais e musicais, honrando a admiração do eu-lírico por sua amante:

um som que seu cabelo faz no meio dos meus dedos

é quase um tom específico de crespo

guardado entre as camadas de uma voz

sua sampleando cada pétala de flores como na sua boca

toda tragédia fosse

virar música de novo (2017, p. 41).

A sinestesia provocada pela mistura de visão (cabelo e flores) e audição (som e voz) para imaginar uma magia através da qual toda tragédia se transforma em música - direito ao devaneio na prática - ressalta a admiração e o prazer do sujeito poético com sua amante.

Outros poemas de Nascimento são mais lúdicos e representam tanto o direito ao prazer quanto o direito à invenção linguística. Esse é o caso, por exemplo, de "quitanda", em que o gosto das frutas se entrelaça à satisfação do coito:

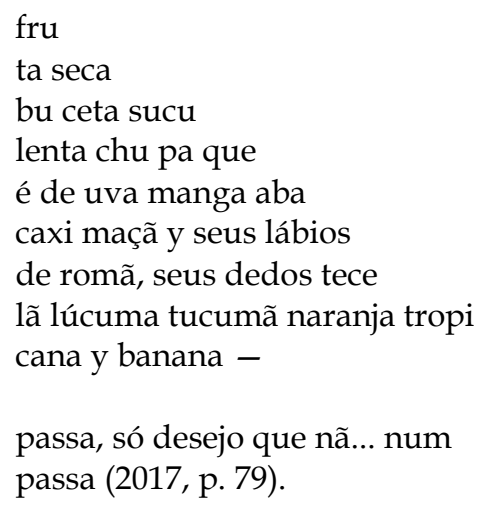

Os fluidos corporais do sexo oral são apresentados de forma descontraída e colorida, como os sumos das frutas. O poema termina com a esperança do eu-poético de que o prazer (do sexo e do sabor das frutas) nunca acabe. Como é comum na poesia de Nascimento, o espanhol se mescla ao português devido ao desejo da autora de reconhecer "um devaneio feminista latino-americano y caribeño", seguindo a tradição de Gonzalez (Nascimento, 2014, p. 9). Esse amálgama linguístico desafia padrões hegemônicos de expressão e permite que a poeta recorra ao espanhol sempre em benefício da sonoridade ou da visualidade dos poemas.

\section{Katiana Souto}

Souto se identifica como negra, "neta de índio" e LGBTQI+ (Souto p. 6; Souto cit. em Maciel, "Conheça") e também publica pela Padê Editorial. Em 2018, lançou escura.noite, uma coletânea que inclui o poema "hoje não teve dor de cabeça". Assim como "quitanda", de Nascimento, o poema de Souto emprega um jogo de palavras, mas aposta na coloquialidade para obtenção de seu efeito: 
hj minha cabeça girou e girou e mergulhou como se fosse mergulho num rio verdim verdim

(bem melhor do que o rio na verdade) pois do rio eu preciso sair alguma hora e em vc eu posso ficar pra sempressa e sem agonia e sem medo d bicho ou de aranha de rio (pq a sua não é peçonhenta e tem gostocheiro bom) e eu moraria sob tua pele até as águas de rio acabarem (2018, p. 30).

A declaração hiperbólica, as abreviações, a informalidade e a brevidade do poema fazem com que ele se assemelhe a uma mensagem de texto enviada a uma amante. Essa característica dá ao poema um tom de urgência, como se o prazer precisasse ser comunicado imediatamente, em uma longa frase. Nascimento, em reflexão sobre a literatura negra e LGBTQI+ publicada pela Padê Editorial, destaca

a responsabilidade e o desafio da nossa produção literária da diáspora e da dissidência sexual na desconstrução/desmonte daqueles dois pilares de opressão: hiperheterocissexualização e silenciamento, pensando essa articulação cuíerlombista que é de resistência enquanto reconstrução, mas também (e talvez principalmente) resistência enquanto devaneio (2018, p. 13).

Embora o poema de Souto não seja abertamente político, sua alegria transbordante honra o que Nascimento chama de "direito ao devaneio" e o que Lorde nomeia como "erótico". Uma vez que essa expressão de alegria deriva do prazer sexual dissidente, o poema também é político, abrindo espaço para definições mais diversas de práticas de prazer.

\section{Cristiane Sobral}

Elaborando sobre o tema do embranquecimento em seu ensaio "Por um feminismo Afrolatino-americano", Gonzalez afirma:

Transmitida pelos meios de comunicação de massa e pelos sistemas ideológicos tradicionais, ela reproduz e perpetua a crença de que as classificações e os valores da cultura ocidental branca são os únicos verdadeiros e universais. [...] o desejo de embranquecer (de "limpar o sangue" como se diz no Brasil), é internalizado com a consequente negação da própria raça e da própria cultura (2021).

A maioria das histórias em $O$ tapete voador (2016), de Sobral - algumas realistas, algumas fantásticas, algumas engraçadas, outras trágicas -, são verdadeiros chamados à resistência contra processos de embranquecimento. O tapete voador pode ser lido como uma comemoração do amorpróprio de mulheres negras brasileiras diante da supremacia branca e do racismo. Em muitas dessas histórias, as mulheres encontram liberdade quando começam a amar seus cabelos, sua pele, sua ancestralidade negra e as práticas de fé diaspóricas, entendendo o amor-próprio como o primeiro passo necessário à transformação social.

Na história cômica "Metamorfose," Socorro, uma mulher negra, simboliza "o desejo de embranquecer" (Gonzalez, 2021). O racismo internalizado da personagem aparece em seu modo de falar e em suas ações. O narrador em terceira pessoa assume a voz de Socorro, usando expressões racistas como "tinham um pé na cozinha" e "cabelo ruim" (Sobral, 2016, p. 89-90). A protagonista desejava ter um marido branco; ouvia música clássica; "usava uma base líquida dois tons mais clara"; alisava o cabelo; sempre vestia "meia-calça branca" e "evitava rodas de samba e cerimônias religiosas afro-brasileiras" (Sobral, 2016, p. 90). Ao descrever a fé cristã de Socorro, através da qual ela via que "a negritude era um verdadeiro desafio para testar os escolhidos à salvação", o narrador aponta o modo com que a protagonista se orientava para a vida: "Socorro aprendera o saber pelo sofrer" (2016, p. 89). Voltando ao ensaio de Lorde, Socorro reprime tanto seus sentimentos a ponto de estar satisfeita com o sofrimento e a autonegação. No entanto, essa perspectiva muda no clímax da história quando, em um ônibus da cidade, o motorista negro Jorge percebe o disfarce autoaniquilante de Socorro. A observação de Jorge de que a "escova progressiva" é "a maior regressão" desperta na protagonista o desejo de autotransformação 
(2016, p. 92). Encharcada por uma tempestade e parada na porta do ônibus, ela finalmente incorpora sua ancestralidade:

Socorro tirou da bolsa uma tesoura pequena e começou a cortar o cabelo. Quanto mais cortava, mais bonita ficava, mais serena, mais incrivelmente consciente. Para o espanto geral, pela primeira vez parecia uma mulher normal, completamente negra e linda. Suas pernas foram finalmente descobertas pela meia-calça rasgada e o rosto não apresentava mais vestígios da maquiagem, desfeita pela força das águas (2016, p. 93).

Socorro convidou então o motorista de ônibus para acompanhá-la até seu carro e, "[e]xtasiada", ela e Jorge "beijaram-se como num apaixonado beijo de cinema" (2016, p. 93). O amor-próprio de Socorro catalisa uma explosão de prazer entre os espectadores:

Todo mundo começou a se beijar no ônibus e no meio do asfalto. A chuva nunca foi tão providencial para algumas mulheres que ali estavam e voluntariamente deixaram a água lavar todo o resquício de embranquecimento, experimentando liberdade para dentro da cabeça (2016, p. 93).

Com o tom de fábula lúdica em que a água tem efeito purificador, a história expressa a catarse do amor-próprio que advém da aceitação da identidade negra e da orientação da vida para o prazer, não para o sofrimento. Pode-se dizer que Socorro aprendera o saber pelo prazer.

Essas afirmações do prazer corporal das mulheres são significativas porque abrem caminho para a normalização desse prazer. Como argumenta Dalcastagnè, no contexto de por que precisamos de escritoras e escritores negros, desconsiderar novas vozes e perspectivas "reforça o papel da literatura como mecanismo de distinção e da hierarquização social, deixando de lado suas potencialidades como discurso desestabilizador e contraditório" (2014, p. 69). Todos os textos analisados mostram que o prazer é político, mas seu foco é a estética, a brincadeira e a conexão erótica e emocional. Além disso, eles têm um traço utópico, já que seus eu-poéticos e suas protagonistas não precisam defender ou esconder seu prazer corporal: elas apenas o apreciam. Termino com Lorde para mostrar como esses textos definem o tom das práticas de prazer das próprias leitoras: Uma vez que começamos a sentir profundamente todos os aspectos de nossas vidas, começamos a esperar de nós mesmas e de nossos propósitos vitais que estejam em acordo com a alegria que nos sabemos capazes de viver" (2019, p. 32). As autoras brasileiras continuam a dar forma às variadas manifestações de práticas de prazer, convidando os leitores a perceber a satisfação corporal como modo de resistência contra a injustiça social.

\section{Referências}

BEAUVOIR, Simone de (1973). The second sex. Tradução de Howard Parshley. Nova Iorque: Vintage Books.

BENSIMON, Carol (2013). Todos nós adorávamos caubóis. São Paulo: Companhia das Letras.

BENSIMON, Carol (2017). O clube dos jardineiros de fumaça. São Paulo: Companhia das Letras.

BRITO, Aline (2019). Referências inspiradoras. Correio Braziliense, Brasília, p. 24, 17 mar.

BROWN, Adrienne Maree (2017). Emergent strategy: shaping change, changing worlds. Chico, Califórnia: AK Press. ProQuest Ebook Central. E-book.

BROWN, Adrienne Maree (org.) (2019). Pleasure activism: the politics of feeling good. Chico, Califórnia: AK Press.

BUTLER, Judith (1990). Gender trouble, feminist theory, and psychoanalytic discourse. In: NICHOLSON, Linda J. (org.). Feminism/Postmodernism. Londres: Routledge. p. 324-340.

DALCASTAGNÈ, Regina (2012). Literatura brasileira contemporânea: um território contestado. Vinhedo: Horizonte.

DALCASTAGNÈ, Regina (2014). Por que precisamos de escritoras e escritores negros? In: SILVA, Cidinha da (org.). Africanidades e relações raciais: insumos para políticas públicas na área do livro, leitura, literatura e bibliotecas no Brasil. Brasília: Fundação Cultural Palmares. p. 66-69. 
DALCASTAGNÈ, Regina; LEAL, Virgínia Maria Vasconcelos (orgs.) (2015). Espaço e gênero na literatura brasileira contemporânea. Porto Alegre: Zouk.

FERREIRA-PINTO, Cristina (2004). Gender, discourse, and desire in twentieth-century Brazilian women's literature. Lafayette, Indiana: Purdue University Press.

FIGUEIREDO, Eurídice (2020). Por uma crítica feminista: leituras transversais de escritoras brasileiras. Porto Alegre: Zouk.

GONZALEZ, Lélia (1988/2021). Por um feminismo afro-latino-americano. Literafro: o portal da literatura afro-brasileira, Belo Horizonte, 3 mar. Disponível em: https://bit.ly/3jNvpFL. Acesso em: 22 set. 2021.

LORDE, Audre (1978/2019). Uses of the erotic. In: BROWN, Adrienne Maree (org.). Pleasure activism: the politics of feeling good. Chico, Califórnia: AK Press. p. 27-35.

MACIEL, Nahima (2018). Conheça a força dos versos femininos do Distrito Federal. Correio Braziliense, Brasília, 12 abr. Disponível em: https:/ / bit.ly/3bl3rfQ. Acesso em: 22 set. 2021.

MCKITTRICK, Katherine (2006). Demonic grounds: black women and the cartographies of struggle. Minneapolis: University of Minnesota Press.

MELO, André Magri Ribeiro; OTHERO, Bruna Kalil; DUARTE, Constância Lima (2019). Poéticas do devirmulher: ensaios sobre escritoras brasileiras. Belo Horizonte: Letramento.

MORAGA, Cherríe (1993). Queer Aztlán: the re-formation of Chicano tribe. In: MORAGA, Cherríe. The last generation. Boston: South End Press. p. 145-174.

NASCIMENTO, Tatiana (2014). Letramento e tradução no espelho de Oxum: teoria lésbica negra em auto/re/conhecimentos. 2014. Tese (Doutorado em Estudos da Tradução) - Universidade Federal de Santa Catarina, Florianópolis. Disponível em: http://repositorio.ufsc.br/handle/123456789/128822. Acesso em: 9 out. 2021.

NASCIMENTO, Tatiana (2017). Lundu,. 2. ed. Brasília: Padê Editorial.

NASCIMENTO, Tatiana (2018). O cuíerlombo da palavra (y da palavra queerlombo...) > poesia preta lgbtqi de denúncia da dor até direito ao devaneio. In: FÁTIMA, Adriana de; SILVA, Susana Souto (org.). Literatura, estética e revolução. Brasília: Universidade de Brasília. p. 7-23.

PIMENTA, Nanda Fer (2018). Sangue. 2. ed. Brasília: Padê Editorial.

RIBEIRO, Djamila (2017). O que é lugar de fala? Belo Horizonte: Letramento.

SÃO BERNARDO, Ana Cláudia dos Santos (2020). From the dumpster to the bookshelf: literature written by black women in Brazil and the quest for mobility in urban spaces from 1960 to the present. 2020. Tese (Doutorado em Spanish and Portuguese Studies) - University of Minnesota, Minneapolis.

SCHNAIDER, Piera (2018). Água viva. Brasília: Padê Editorial.

SENA, Kika (2017). Periférica. Brasília: Padê Editorial.

SOBRAL, Cristiane (2016). Metamorfose. In: SOBRAL, Cristiane. O tapete voador. Rio de Janeiro: Malê. p. 89-93.

SOUTO, Katiana (2018). Escura.noite. Brasília: Padê Editorial.

TENNINA, Lucía (2015). A voz e a letra da mulher na literatura marginal periférica: figurações e reconfigurações do eu. In: DALCASTAGNÈ, Regina; LEAL, Virgínia Maria Vasconcelos (org.). Espaço e gênero na literatura brasileira contemporânea. Porto Alegre: Zouk. p. 57-83.

TENNINA, Lucía (2017). Cuidado com os poetas! Literatura e periferia na cidade de São Paulo. Tradução de Ari Pimentel. Porto Alegre: Editora Zouk.

VALENTINE, Gill (1996). (Re)negotiating the "heterosexual street": lesbian production of space. In: DUNCAN, Nancy (org.). BodySpace: destabilising geographies of gender and sexuality. Londres: Routledge. p. $145-154$ 